\title{
Improved outcomes with the comprehensive stage 2 procedure after an initial hybrid stage 1
}

\author{
Mark Galantowicz, MD, ${ }^{\mathrm{a}, \mathrm{b}, \mathrm{d}}$ and Andrew R. Yates, $\mathrm{MD}^{\mathrm{a}, \mathrm{c}, \mathrm{e}}$
}

\section{ABSTRACT}

Objective: To report our improving institutional experience with the hybrid alternative surgical strategy for the management of hypoplastic left heart syndrome, in which hybrid stage 1 is followed by a comprehensive stage 2 procedure (removal of patent ductus arteriosus stent and pulmonary artery [PA] bands, aorta and PA reconstruction, Damus-Kaye-Stansel, atrial septectomy, Glenn).

Methods: In this Institutional Review Board-approved retrospective review of all patients undergoing a comprehensive stage 2 procedure between January 2002 and December 2014, data were compared between the pre-protocol group ( $\mathrm{n}=64$; January 2002 to March 2010) and the post-protocol group ( $\mathrm{n}=55$; March 2010 to December 2014). These 2 groups flank the implementation of a perioperative management protocol to prevent PA thrombosis.

Results: Pre-protocol mortality was 19\% (12 of 64), with the most common mode of death involving PA thrombosis in at least 7 patients, with an urgent indication for surgery and age as contributing factors. Care modifications instituted in March 2010 included avoidance of procedures on an emergent basis or in patients aged $<3$ months, use of a systemic PA shunt in cases of too-small superior vena cava and/or PA, completion angiogram with a low threshold for intraoperative stenting, and postoperative anticoagulation therapy for 6 weeks. There was a significant decrease in mortality ( 2 of $55 ; 4 \% ; P=.01$ ), PA thrombosis $(0$ of $55 ; 0 \% ; P=.01)$, and use of extracorporeal membrane oxygenation $(0 / 55[0 \%]$ compared with 7 of $64[11 \%] ; P=.01)$ after protocol implementation.

Conclusions: Despite the technical challenges of the comprehensive stage 2 procedure, excellent outcomes are attainable. Experience coupled with an internal quality review drove the implementation of a successful perioperative management protocol. (J Thorac Cardiovasc Surg 2016;151:424-9)

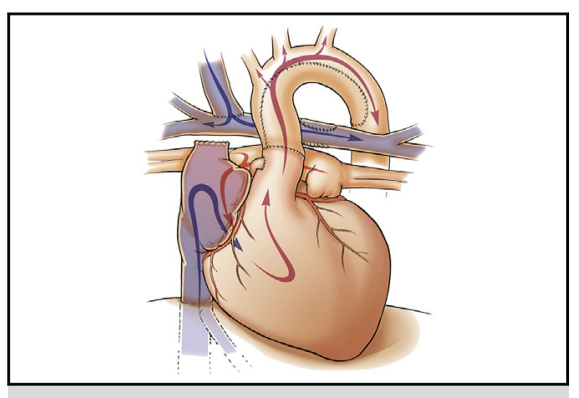

Comprehensive stage 2 procedure

\section{Central Message}

Significantly improved outcomes for the comprehensive stage 2 procedure following an initial hybrid stage 1 procedure have been demonstrated with the implementation of a perioperative protocol focused on eliminating pulmonary artery thrombosis.

\section{Perspective}

The hybrid approach has emerged as an alternative surgical strategy for the management of hypoplastic left heart syndrome. A hybrid stage 1 is followed by a comprehensive stage 2 procedure. This is a challenging new procedure with very little published outcome data. We report our improving institutional experience.

See Editorial Commentary page 430.
The hybrid approach has emerged as an alternative surgical strategy for the management of hypoplastic left heart syndrome (HLHS). ${ }^{1-4}$ The initial hybrid stage 1 combines the surgical placement of branch pulmonary

\footnotetext{
From the ${ }^{\mathrm{a} H e a r t}$ Center at Nationwide Children's Hospital, ${ }^{\mathrm{b}}$ Department of Cardiothoracic Surgery, and ${ }^{\mathrm{c}}$ Division of Cardiology and Critical Care, Nationwide Children's Hospital, Columbus, Ohio and Departments of ${ }^{\mathrm{d}}$ Surgery and ${ }^{\mathrm{e}}$ Pediatrics, Ohio State University, Columbus, Ohio.

Read at the 95th Annual Meeting of The American Association for Thoracic Surgery, Seattle, Washington, April 25-29, 2015.

Received for publication April 27, 2015; revisions received Sept 26, 2015; accepted for publication Oct 2, 2015; available ahead of print Dec 2, 2015.

Address for reprints: Mark Galantowicz, MD, Department of Cardiothoracic Surgery, Nationwide Children's Hospital, 700 Children's Dr, Suite T2295, Columbus, OH 43205 (E-mail: mark.galantowicz@nationwidechildrens.org).

$0022-5223 / \$ 36.00$

Copyright (c) 2016 by The American Association for Thoracic Surgery

http://dx.doi.org/10.1016/j.jtcvs.2015.10.023
}

artery (PA) bands with transcatheter placement of a patent ductus arteriosus (PDA) stent and balloon atrial septostomy. The subsequent surgery, often referred to as a comprehensive stage 2 or combined Norwood 1 and 2, involves removal of the PA bands with possible PA reconstruction, removal of the PDA stent with aortic arch reconstruction, a Damus-Kaye-Stansel connection of the aortic and PA roots, a bidirectional superior cavopulmonary connection, and an atrial septectomy

Scanning this QR code will take you to the article title page. 


\section{Abbreviations and Acronyms \\ $\mathrm{ECMO}=$ extracorporeal mechanical oxygenation \\ HLHS $=$ hypoplastic left heart syndrome \\ PA = pulmonary artery \\ PDA $=$ patent ductus arteriosus \\ $\mathrm{SVC}=$ superior vena cava}

(Figure 1). This challenging new procedure is critical to the overall success of the hybrid approach. Here we share our institutional experience with the comprehensive stage 2 procedure, with attention given to our significantly improved outcomes after the institution of a perioperative management protocol focused on reducing or eliminating PA thrombosis.

\section{METHODS}

This was an Institutional Review Board-approved retrospective review of prospectively collected data on all patients undergoing a comprehensive stage 2 procedure between January 2002 and December 2014. The patients were separated into 2 chronological cohorts based on the implementation of a new perioperative management protocol: pre-protocol, from January 2002 to March $2010(\mathrm{n}=64)$ and post-protocol, from March 2010 to December $2014(\mathrm{n}=55)$. Excluded from this analysis were any patients palliated with a hybrid stage 1 procedure who then underwent a 2-ventricle repair.

In early 2010, as part of our Heart Center's quality improvement initiative, we evaluated the causes of death in patients who had undergone a comprehensive stage 2 procedure. This analysis revealed that the most common mode of death involved the development of PA thrombosis during the postoperative period. Further analysis of this subgroup of patients who developed a confirmed PA thrombus did not reveal any predictive perioperative factors. Preoperative factors assessed included diagnosis, age, weight, saturation, comorbid diagnoses, ventricular function and/or tricuspid regurgitation, and characteristics of flow through the PA bands and through the PDA stent. Intraoperative factors considered included bypass and crossclamp times; PA and aortic arch reconstruction techniques; immediate postoperative bleeding with resultant treatment, including any use of activated factor VII; immediate cardiac function; oxygen saturation; and inotrope use. Initial postoperative intensive care unit factors considered included cardiac/pulmonary/renal function, intubation time, fluid balance, inotrope score, and use of anticoagulation. Again, no preoperative, intraoperative, or postoperative factor was predictive of or associated with the development of a PA thrombus, yet the consequence of its development was severe. Therefore, we initiated a preventive strategy in March 2010, as outlined in Table 1. The goal of this protocol was to prevent the development of PA thrombus formation with its significant impact on morbidity and mortality.

Other measures identified from the quality initiative review of the pre-protocol patients were also instituted at this time. These included refraining from performing a comprehensive stage 2 procedure in patients aged $<3$ months or as an emergent procedure in decompensating patients who had undergone a hybrid stage 1 procedure. In addition, instead of proceeding with the standard comprehensive stage 2 procedure as described above in all patients regardless of intraoperative findings, in patients in whom the PA and/or superior vena cava (SVC) was too small to allow safe creation of a reliable cavopulmonary

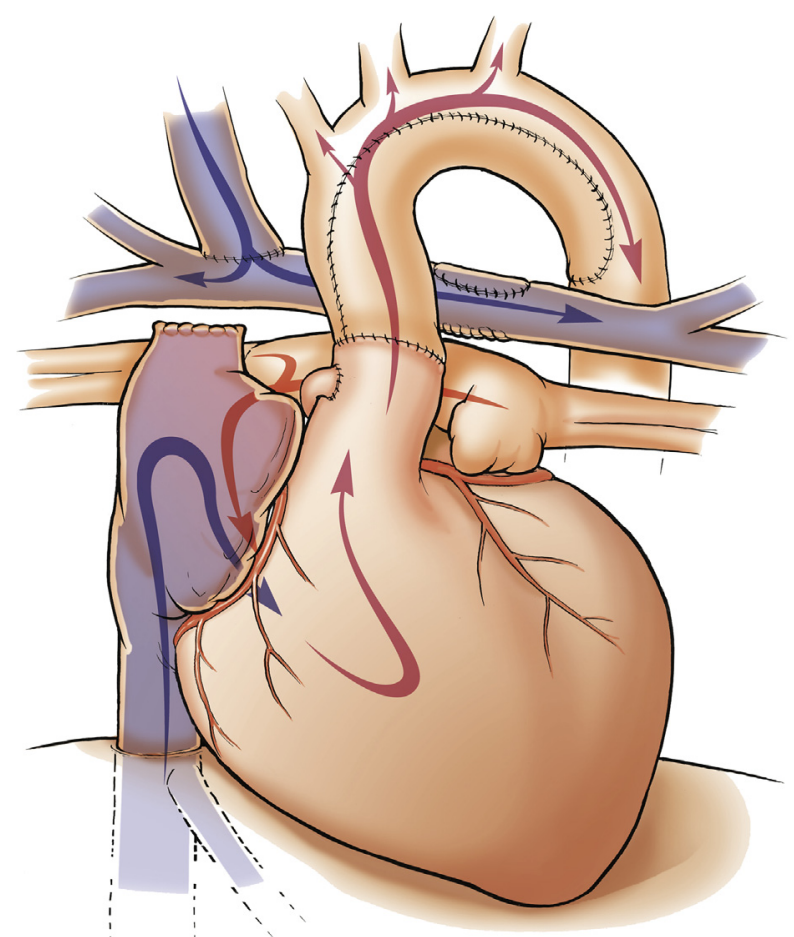

FIGURE 1. Completed comprehensive stage 2.

connection, if necessary the procedure was modified, with the use of a systemic-to-PA shunt as a source of pulmonary blood flow.

Eight patients in the pre-protocol group required hospital admission immediately before undergoing the comprehensive stage 2 procedure. Reasons for admission included vomiting and feeding issues in 3 patients, decreased function and preoperative inotropic support in 2 patients, no discharge from the hospital in 1 patient, and cyanosis in 2 patients.

Finally, although the general operative procedure was the same in the 2 groups, performed on bypass with no use of circulatory arrest, ${ }^{5,6}$ the technique was modified for some patients in the post-protocol group. In these patients, the entire operation was performed on bypass with no cross-clamping or circulatory arrest, using an additional aortic root cannula coupled with antegrade cerebral perfusion.

Categorical data were compared using Fisher's exact test. Continuous data were analyzed using the Mann-Whitney $U$ test or a 2tailed $t$ test depending on the results of the D'Agostino and Pearson omnibus normality test. The effects of time and experience were assessed using logistical regression with Firth's penalized likelihood to account for rare events. A $P$ value $<.05$ was considered significant in all analyses.

\section{RESULTS}

Twelve patients died before implementation of the protocol, with most deaths related to the morbid consequences of a PA thrombus. PA thrombus was confirmed in 7 patients by catheterization and suspected in 2 others (Figure 2). A detailed analysis of these patient's perioperative characteristics revealed no predictive factor for PA thrombus formation. The next most common mode of death involved emergent or early surgery 
TABLE 1. Comprehensive stage 2 perioperative protocol

\section{Preoperative}

a. Comprehensive stage 2 ideally at age $5 \mathrm{mo}$, but not $<3 \mathrm{mo}$

b. No emergent comprehensive stage 2 procedures

2. Intraoperative

a. If superior vena cava and/or branch pulmonary arteries smaller than expected, consider a systemic-pulmonary shunt

b. Completion angiogram to evaluate cavopulmonary connection and branch pulmonary artery flow

i. Low threshold for surgical revision or stent placement if evidence of stenosis

ii. Angiograms graded by surgeon/interventionalist as immediate treatment necessary, no treatment necessary, or additional evaluation at $6 \mathrm{wk}$ postoperatively

3. Postoperative

a. Early extubation. If still intubated at $72 \mathrm{~h}$ postoperatively, obtain additional imaging of pulmonary vasculature

b. Postoperative anticoagulation

i. Initiate heparin at $24 \mathrm{~h}$ postoperatively

ii. Transition to enoxaparin for $6 \mathrm{wk}$

iii. Aspirin therapy on completion of enoxaparin course

c. Consider additional pulmonary artery imaging before transitioning from enoxaparin if operative angiogram warrants reevaluation

for a failing hybrid stage 1 procedure in 4 patients. A review identified the most likely reason for these patients' previous surgery as retrograde aortic arch stenosis, which we subsequently learned how to detect and treat. $^{7,8}$

Demographic characteristics of the 2 study groups are highlighted in Table 2. The between-group differences

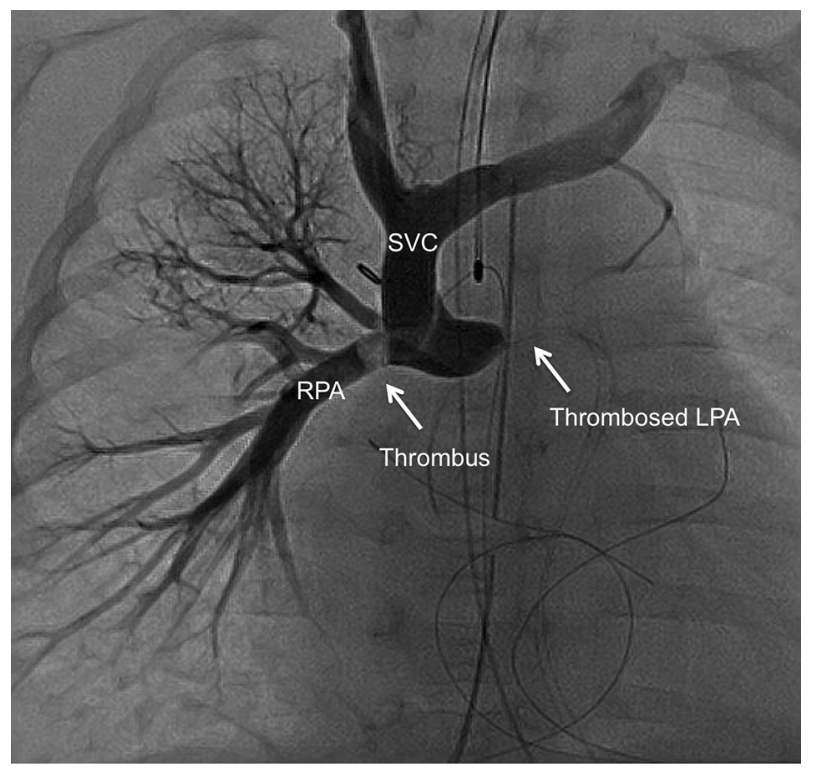

FIGURE 2. Group 1 patient with a PA thrombus. $S V C$, Superior vena cava; $R P A$, right pulmonary artery; $L P A$, left pulmonary artery.
TABLE 2. Patient demographic data

\begin{tabular}{lccc}
\hline \multicolumn{1}{c}{ Characteristic } & $\begin{array}{c}\text { Pre-protocol } \\
(\mathbf{n = 6 4 )}\end{array}$ & $\begin{array}{c}\text { Post-protocol } \\
(\mathbf{n = 5 5})\end{array}$ & $\boldsymbol{P}$ value \\
\hline Age, mo, mean SD & $5.6 \pm 1.4$ & $5.9 \pm 1.9$ & .91 \\
Weight, kg, mean SD & $5.7 \pm 0.9$ & $6.6 \pm 1.0$ & $<.0001$ \\
Female sex, n (\%) & $23(37)$ & $20(36)$ & 1.00 \\
$\begin{array}{l}\text { Bypass time, min, } \\
\quad \text { median (IQR) }\end{array}$ & $283.5(250-331)$ & $243(225-275)$ & $<.0001$ \\
$\begin{array}{l}\text { Cross-clamp time, } \\
\text { min, median (IQR) }\end{array}$ & $85(69.5-104.8)$ & $0(0-48)$ & $<.0001$ \\
$\begin{array}{l}\text { Significant } P \text { values are in bold type. } S D, \text { Standard deviation; } I Q R, \text { interquartile range. }\end{array}$
\end{tabular}

in age and weight are consistent with the protocol initiative to refrain from performing early comprehensive stage 2 procedures. The shorter bypass and cross-clamp times are consistent with experience and the modification of the procedure as outlined. Of note, 28 of 55 patients $(51 \%)$ in the post-protocol group underwent the comprehensive stage 2 procedure on bypass with no period of cross-clamping. Circulatory arrest was performed in only 5 of 64 patients $(8 \%)$ in the pre-protocol group and in only 1 of 55 patients $(2 \%)$ in the post-protocol group. Circulatory arrest was used predominantly early in the learning curve, with the first 4 patients in the pre-protocol group representing the majority of these cases.

Primary outcomes are listed in Table 3. Of note, there were no cases of PA thrombosis post-protocol, which contributed to the significantly lower mortality rate in this group compared with the pre-protocol group $(4 \%$ vs $19 \% ; P=.01)$. The 2 deaths occurring in the postprotocol group were the result of multisystem organ failure after the development of a fulminant rhinovirus infection in 1 patient and arrhythmic cardiac arrest in the other patient. Data on all of the patients from both groups who died are provided in Table 4.

Given the longitudinal data collection and the potential for surgical outcomes to improve with experience, logistical regression with Firth's penalized likelihood to

TABLE 3. Outcomes

\begin{tabular}{lccc}
\hline \multicolumn{1}{c}{ Variable } & $\begin{array}{c}\text { Pre-protocol } \\
(\mathbf{n = 6 4 )}\end{array}$ & $\begin{array}{c}\text { Post-protocol } \\
(\mathbf{n}=\mathbf{5 5})\end{array}$ & $\boldsymbol{P}$ value \\
\hline Mortality, n (\%) & $12(19)$ & $2(4)$ & $\mathbf{. 0 1}$ \\
PA thrombosis, n (\%) & $7(11)$ & 0 & $\mathbf{. 0 1}$ \\
Postoperative ECMO, n (\%) & $7(11)$ & 0 & $\mathbf{. 0 1}$ \\
Bleeding, n (\%)* & $10(16)$ & $3(5)$ & .09 \\
ICU LOS, d, median (IQR) & $4.5(3-9.75)$ & $5(3-10)$ & .83 \\
Hospital LOS, d, median (IQR) & $9(7-16.75)$ & $13(8-22)$ & $\mathbf{. 0 1}$ \\
\hline
\end{tabular}

Significant $P$ values are in bold type. $E C M O$, Extracorporeal membrane oxygenation; $I C U$, intensive care unit; $L O S$, length of stay; $I Q R$, interquartile range. *Bleeding complication was defined as evidence of a new hemorrhage on brain imaging or systemic bleeding requiring a transfusion. 
TABLE 4. Patient mortality and associated morbidity

\begin{tabular}{|c|c|c|c|c|c|c|c|c|c|c|c|c|c|}
\hline Patient & $\begin{array}{c}\text { Age, } \\
\text { mo }\end{array}$ & $\begin{array}{c}\text { Weight, } \\
\text { kg }\end{array}$ & Sex & Diagnosis & $\begin{array}{l}\text { Admit } \\
\text { preop }\end{array}$ & $\begin{array}{l}\text { Open } \\
\text { chest }\end{array}$ & $\begin{array}{c}\text { Ever } \\
\text { extubated }\end{array}$ & Arrest & ECMO & Dialysis & Infection & $\begin{array}{c}\text { PA } \\
\text { thrombus }\end{array}$ & $\begin{array}{l}\text { POD o } \\
\text { death }\end{array}$ \\
\hline \multicolumn{14}{|c|}{ Pre-protocol } \\
\hline 1 & 2 & 3.6 & $\mathrm{~F}$ & HLHS & $\mathrm{Y}$ & $\mathrm{Y}$ & $\mathrm{N}$ & $\mathrm{Y}$ & $\mathrm{Y}$ & $\mathrm{Y}$ & Airway, Enterobacter & $\mathrm{N}$ & 16 \\
\hline 2 & 3 & 4.6 & F & HLHS & $\mathrm{Y}$ & $\mathrm{Y}$ & $\mathrm{N}$ & $\mathrm{N}$ & Y & Y & $\begin{array}{c}\text { Airway, Staphylococcus; } \\
\text { blood, Pseudomonas }\end{array}$ & Y & 6 \\
\hline 3 & 4 & 5.7 & M & HLHS & $\mathrm{N}$ & $\mathrm{Y}$ & $\mathrm{N}$ & $\mathrm{N}$ & $\mathrm{N}$ & $\mathrm{N}$ & None & $\mathrm{N}$ & 7 \\
\hline 4 & 7 & 5.9 & M & HLHS & $\mathrm{N}$ & $\mathrm{N}$ & $\mathrm{Y}$ & $\mathrm{Y}$ & $\mathrm{Y}$ & $\mathrm{Y}$ & Blood, Serratia & $\mathrm{Y}$ & 15 \\
\hline 5 & 5.5 & 6.6 & M & HLHS & $\mathrm{N}$ & $\mathrm{N}$ & $\mathrm{N}$ & $\mathrm{Y}$ & $\mathrm{N}$ & $\mathrm{N}$ & Blood, Serratia & $\mathrm{Y}$ & 6 \\
\hline 6 & 6.5 & 4.9 & $\mathrm{~F}$ & HLHS & $\mathrm{N}$ & $\mathrm{N}$ & $\mathrm{N}$ & Y & $\mathrm{N}$ & $\mathrm{N}$ & None & $\mathrm{N}$ & 1 \\
\hline 7 & 6 & 5 & M & HLHS & $\mathrm{N}$ & $\mathrm{Y}$ & $\mathrm{N}$ & Y & Y & $\mathrm{Y}$ & Airway, Pseudomonas & $\mathrm{N}$ & 9 \\
\hline 8 & 8 & 5 & $\mathrm{~F}$ & $\begin{array}{l}\text { TAPVR, AVSD, } \\
\text { AA }\end{array}$ & $\mathrm{Y}$ & $\mathrm{Y}$ & $\mathrm{N}$ & $\mathrm{Y}$ & $\mathrm{Y}$ & $\mathrm{Y}$ & $\begin{array}{l}\text { Airway and urinary } \\
\text { tract, Pseudomonas }\end{array}$ & $\mathrm{Y}$ & 14 \\
\hline 9 & 6 & 6.25 & $\mathrm{~F}$ & HLHS & $\mathrm{Y}$ & $\mathrm{Y}$ & $\mathrm{N}$ & Y & $\mathrm{N}$ & $\mathrm{N}$ & None & $\mathrm{Y}$ & 5 \\
\hline 10 & 4 & 5.8 & M & HLHS & $\mathrm{Y}$ & $\mathrm{Y}$ & $\mathrm{N}$ & $\mathrm{N}$ & $\mathrm{N}$ & $\mathrm{N}$ & Airway, Enterococcus & $\mathrm{N}$ & 35 \\
\hline 11 & 4 & 5.3 & M & HLHS & $\mathrm{Y}$ & $\mathrm{N}$ & $\mathrm{N}$ & $\mathrm{Y}$ & $\mathrm{N}$ & $\mathrm{N}$ & None & $\mathrm{Y}$ & 17 \\
\hline 12 & 5 & 6.45 & $\mathrm{~F}$ & HLHS & $\mathrm{N}$ & $\mathrm{N}$ & $\mathrm{N}$ & $\mathrm{Y}$ & $\mathrm{N}$ & $\mathrm{N}$ & None & $\mathrm{Y}$ & 9 \\
\hline \multicolumn{14}{|c|}{ Post-protocol } \\
\hline 13 & 5 & 6.4 & M & HLHS & $\mathrm{N}$ & $\mathrm{N}$ & $\mathrm{Y}$ & $\mathrm{Y}$ & $\mathrm{N}$ & $\mathrm{N}$ & $\begin{array}{l}\text { Airway, rhinovirus and } \\
\text { Pseudomonas }\end{array}$ & $\mathrm{N}$ & 14 \\
\hline 14 & 5 & 5.9 & M & HLHS & $\mathrm{N}$ & $\mathrm{N}$ & $\mathrm{N}$ & $\mathrm{Y}$ & $\mathrm{N}$ & $\mathrm{N}$ & Airway, Moraxella & $\mathrm{N}$ & 10 \\
\hline
\end{tabular}

Admit Preop is defined as required admission to the hospital before undergoing surgical repair. Open chest is defined as sternum left open at conclusion of operative case. Ever extubated is defined as endotracheal extubation for $>24$ hours. Arrest is defined as the need for cardiac compressions. Infection is defined as a positive culture treated with antibiotics. PA thrombus was documented by cardiac catheterization or chest computed tomography scan. ECMO, Extracorporeal mechanical oxygenation; $P A$, pulmonary artery; $P O D$, postoperative day; $H L H S$, hypoplastic left heart syndrome; TAPVR, total anomalous pulmonary venous return; AVSD, atrioventricular septal defect; $A A$, aortic atresia.

account for infrequent events was used. Our analysis found that the odds of death after the procedure were 5.1-fold greater in the pre-protocol group compared with the post-protocol group (95\% CI for OR, 1.228-21.131; $P=.02$ ). In addition, there was no significant relationship between the decline in mortality over the entire study period (OR, 1 ; 95\% CI, 0.999-1; $P=.07$ ). Similarly, analysis of the pre-protocol and post-protocol groups did not reveal any significant relationship between mortality and time $(P=.6244$ and .9174 for the pre-protocol and post-protocol eras, respectively).

The potential risk of increased bleeding complications with the institution of a 6-week anticoagulation protocol was tracked. There was no increase in bleeding complications in the post-protocol group. The 3 bleeding complications post-protocol included 1 gastrointestinal bleed, 1 subdural bleed, and 1 cerebellar intracranial bleed, all of which were successfully managed by temporary cessation of anticoagulation, with no surgical or neurosurgical procedures required. The patient who suffered cerebellar hemorrhage had multisystem organ failure, including the development of elevated pulmonary vascular resistance (on catheterization) from fulminant rhinovirus. The other 2 patients had no long-term sequellae related to anticoagulation.

Intraoperative completion angiography of the cavopulmonary anastomosis was performed in 50 of the 55 patients
$(91 \%)$ in the post-protocol group. Of these 50 patients, 1 patient underwent revision of the aortic arch reconstruction owing to compression of the left PA, and 3 patients underwent intraoperative stent placement in the left PA (Figures 3 and 4).

During the post-protocol era (March 2010 to December 2014), 6 patients underwent an alternative procedure

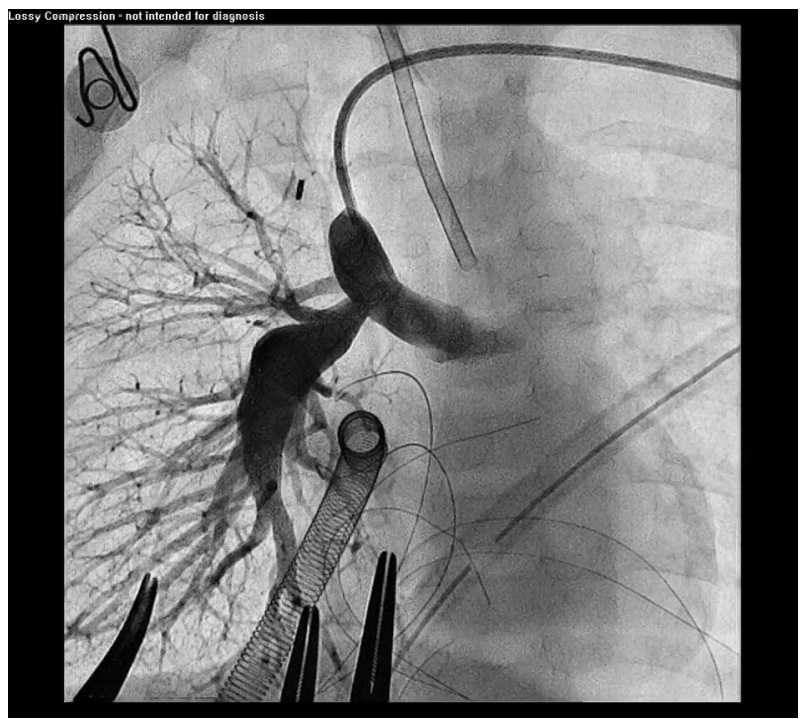

FIGURE 3. Completion angiogram demonstrating reduced flow into the left PA secondary to a twist/fold. 


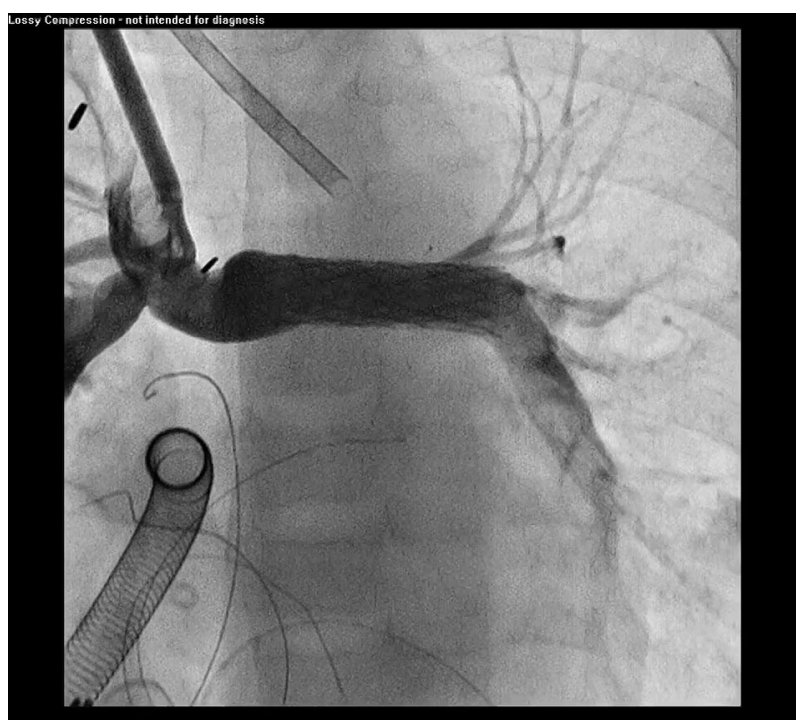

FIGURE 4. Normal flow after intraoperative placement of a left PA stent.

rather than proceeding to the comprehensive stage 2 procedure. During the planned comprehensive stage 2 procedure, 3 patients were found to have a PA or SVC deemed too small to allow a reliable cavopulmonary connection and were managed with a systemic-to-PA shunt. This was an intraoperative judgment based on anatomic findings, such as small SVCs in a patient with bilateral SVCs and small SVCs in a former preterm infant $(1.3 \mathrm{~kg})$ with a previous SVC line. These patients subsequently underwent a successful traditional Glenn procedure. An additional 3 patients during this time period were aged $<3$ months with significant retroaortic arch stenosis not amenable to transcatheter therapy. These patients underwent a modified surgical procedure in which the aortic arch was reconstructed while leaving the PA bands in place. These patients then went on to a successful PA debanding, Glenn, or Damus-Kaye-Stansel procedure.

\section{DISCUSSION}

Although the hybrid approach for the surgical management of HLHS has emerged as an alternative strategy, most of the published outcomes have focused either on results of the initial hybrid stage 1 procedure or results in high-risk patients. The only other large series of comprehensive stage 2 results are from centers in Giessen, Germany $^{3}$ and Toronto, Canada, ${ }^{9}$ reporting mortality rates of $9 \%$ ( 8 of 89$)$ and $6 \%$ ( 2 of 32$)$, respectively. Optimizing the outcomes with the comprehensive stage 2 procedure is critical to the overall success of the hybrid approach and to its wider implementation. At its core, the comprehensive stage 2 procedure combines the traditional Norwood and Glenn procedures; however, certain elements are unique to the new procedure, including PDA stent removal and its potential impact on aortic arch reconstruction, as well as the potential consequences of the previous PA bands. Our experience with more than 100 comprehensive stage 2 procedures leads us to conclude that the key to success is creating an unobstructed central PA confluence.

Several anatomic elements are related to the surgical execution of a comprehensive stage 2 procedure that may put a patient at risk for PA thrombosis. First, there is redundancy of the main PA aspect between the branch PA bands and the PDA stent, which leads to excessive PA tissue as well as a more acute angle between the right and left PA origins that must be contoured in the reconstruction. The second anatomic difference is the junction of the aortic arch-PDA stent seems to move posteriorly-inferiorly around the curve of the aorta as the child grows, causing more crowding around the left PA than occurs in a neonate. In addition to the anatomic challenges, the physiological changes resulting from the procedure put the patient at risk, owing to endothelial injury from the resultant PA reconstruction and cavopulmonary artery connection with suture lines, patch material, and nontubular elements, creating a disrupted endovascular bed with often nonlaminar, nonpulsatile, low-pressure flow. The lower-flow state and surgical endothelial injury, coupled with the inflammatory response from cardiopulmonary bypass as well as the anatomic challenges, combine to put the patient at risk for PA thrombosis, which our analysis identified as the primary cause of a poor outcome.

The perioperative protocol that we instituted attempts to address those modifiable risks as well as reduce the patient-specific risks. Patient selection was modified by moving away from any early (age $<3$ months) or emergent (in patients requiring hospitalization before surgery) comprehensive stage 2 procedures, thereby improving the likelihood of a low-resistant pulmonary vascular bed with improved forward flow. Intraoperative assessment of PA and SVC size requires judgment regarding adequate flow through the resulting cavopulmonary connection and is typically an issue in former preterm infants or those with bilateral SVCs. Using a systemicto-PA shunt in that situation has proven to be a good option.

The routine use of a completion angiogram before disconnecting from bypass has been a very important tool for improving postoperative outcomes in this patient population. Although transesophageal echocardiography is used routinely, this technique cannot fully assess the new cavopulmonary-to-PA reconstruction and flow patterns into both lungs. Moreover, although the surgeon can visually assess these connections before the amalgamation of the neo-aortic root to aortic arch reconstruction, their 
final orientation cannot be visualized directly at the end of the procedure, allowing for a twist, compression, or other compromise of flow to possibly go undetected. An angiogram with a small (5 Fr) catheter in the innominate vein can quickly and safely assess the entire cavopulmonary reconstruction and flow. Moreover, this same access can be used to perform stenting of any areas of stenosis, leading to improved forward flow.

The 6-week course of anticoagulation therapy is based on the assumption that the endovascular milieu is perturbed after the comprehensive stage 2 procedure not only macroscopically, but also at the cell level, increasing the risk of thrombus formation. Therefore, preventing thrombus formation with anticoagulation during the period of cellular regeneration is indicated. The potential downside of significant bleeding complications was considered, tracked, and turned out not to be a problem.

Comparisons of the hybrid approach for palliation of single ventricle physiology to other palliative strategies have been limited. With our improved outcomes for patients with the comprehensive stage 2 intervention, the contemporary expectations for patients palliated with this surgical strategy would be expected to be better than patients 5 to 10 years before protocol implementation. Results for patients continue to improve and thus necessitate comparisons of palliative strategies requiring contemporaneous patient populations in the future.

\section{CONCLUSIONS}

Excellent outcomes with the comprehensive stage 2 procedure can be attained. The use of a perioperative protocol focused on reducing the incidence of PA thrombosis is instrumental in optimizing outcomes.

\section{Conflict of Interest Statement}

The authors have nothing to disclose with regard to commercial support.

We thank Roberta Rodeman, BSN and Tamara D. Clark, DNP for their assistance with database management and analysis as well, and Melissa Moore-Clingenpeel for her assistance with the statistical analyses.

\section{References}

1. Galantowicz M, Cheatham JP, Phillips A, Cua CL, Hoffman TM, Hill SL, et al Hybrid approach for hypoplastic left heart syndrome: intermediate results after the learning curve. Ann Thorac Surg. 2008;85:2063-71.

2. Galantowicz M. In favor of the hybrid stage 1 as the initial palliation for hypoplastic left heart syndrome. Semin Thorac Cardiovasc Surg Pediatr Card Surg Ann. 2013;16:62-4.

3. Schranz D, Bauer A, Reich B, Steinbrenner B, Recla S, Schmidt D, et al Fifteen-year single-center experience with the "Giessen hybrid" approach for hypoplastic left heart and variants: current strategies and outcomes. Pediatr Cardiol. 2015:36:365-73.

4. Venugopal PS, Luna KP, Anderson DR, Austin CB, Rosenthal E, Krasemann T, et al. Hybrid procedure as an alternative to surgical palliation of high-risk infants with hypoplastic left heart syndrome and its variants. J Thorac Cardiovasc Surg. 2010;139:1211-5.

5. Galantowicz M. The hybrid approach to hypoplastic left heart syndrome. Op Techn Thorac Cardiovasc Surg. 2009; 14:74-85.

6. Galantowicz M, Cheatham JP. A hybrid strategy for the initial management of hypoplastic left heart syndrome: technical considerations. In: Sievert $\mathrm{H}$, Qureshi SA, Wilson N, Hijazi ZM, eds. Percutaneous Interventions for Congenital Heart Disease. London: Informa Healthcare; 2007:531-8.

7. Stoica SC, Phillips AB, Egan M, Rodeman R, Chisolm J, Hill SL, et al. The retrograde aortic arch in the hybrid approach to hypoplastic left heart syndrome. Ann Thorac Surg. 2009;88:1939-46.

8. Egan MJ, Hill SL, Boettner BL, Holzer RJ, Phillips AB, Galantowicz M, et al. Predictors of retrograde aortic arch obstruction after hybrid palliation of hypoplastic left heart syndrome. Pediatr Cardiol. 2011;32:67-75.

9. Baba K, Kotani Y, Chetan D, Chaturvedi R, Lee K, Benson L, et al. Hybrid versus Norwood strategies for single-ventricle palliation. Circulation. 2012;126:S123-31.

Key Words: hypoplastic left heart syndrome, hybrid approach 